\title{
Photosynthetic responses to temperature of two tropical rainforest tree species from Costa Rica
}

\author{
German Vargas G $\cdot$ Roberto A. Cordero S
}

Received: 9 November 2012/Revised: 11 February 2013 / Accepted: 28 March 2013

(C) Springer-Verlag Berlin Heidelberg 2013

\begin{abstract}
Annual mean temperature increases will cause alterations in many ecosystem processes, which affect plants given their physiological sensitivity to temperature. That is closely related with plant growing conditions, genotype and plasticity. We studied the photosynthetic responses to instantaneous temperature changes and functional leaf traits in two tropical tree species associated with different successional positions, Zygia longifolia (early successional) and Dipteryx oleifera (late successional), in the northern lowlands of Costa Rica. We found that D. oleifera had thicker leaves and lower stomatal density, but similar specific leaf area to Z. longifolia. Maximum photosynthetic rate $\left(A_{\max }\right)$ and maximum RuBP saturate rate of carboxylation were higher in Z. longifolia than in D. oleifera. At $37^{\circ} \mathrm{C}$, only Z. longifolia reduced $A_{\max }$ and water use efficiency (WUE). But D. panamensis presented more severe effects on the quantum yield, respiration and light compensation points. The temperature response curves showed a similar optimum temperature near $27{ }^{\circ} \mathrm{C}$ for both species. On the other hand, the low and high temperature compensation points were different, with $D$. oleifera showing a narrower range than $Z$. longifolia. As a whole, we found two different strategies to avoid temperature stress: one reducing WUE ( $Z$. longifolia), and the other one increasing metabolic rates $(D$. oleifera). However, the ability to withstand stressful situations may, in a larger context, negatively affect ecosystem water and carbon fluxes. Also, functional plasticity in response to temperature changes may relatively affect the ecosystem by
\end{abstract}

Communicated by H. Pfanz.

G. Vargas $G(\bowtie) \cdot R$. A. Cordero S

Laboratorio de Ecología Vegetal Funcional (LEVEF), Escuela

de Ciencias Biológicas, Facultad de Ciencias Exactas y

Naturales, Universidad Nacional, Heredia, Costa Rica

e-mail: gevargu@gmail.com causing long-term variations in their representation within the complex diversity mosaic of their forest habitats.

Keywords Functional plasticity · High temperature stress - Leaf thickness - Water use efficiency

\section{Introduction}

The annual increase of greenhouse gases emissions and in particular of carbon dioxide $\left(\mathrm{CO}_{2}\right)$ is a direct consequence of human activity ( $\mathrm{Li}$ et al. 2011), which cause a rise in mean annual temperature, leading to many alterations in the exchange of gases in many ecosystems (Bonan 2008; Lammertsma et al. 2011). Tropical rain forests are complex ecosystems that have numerous interactions between their components. One very important interaction is the balance between assimilation of $\mathrm{CO}_{2}$ and its liberation in decomposition and respiration processes, through the carbon cycle. Recent studies suggest that increases in mean annual temperature reduce $\mathrm{CO}_{2}$ uptake by tropical rainforest trees (Clark 2004). When ambient temperatures increase, plants may undergo excessive heat stress, which can have adverse consequences on plant growth, survival. Photosynthesis is a highly sensitive physiological process that responds in different ways to environmental changes (Kurek et al. 2007). An important consequence of heat stress is an inhibition of the photosynthetic apparatus (Sharkey 2005). The main effect of that inhibition is a considerable decline of $\mathrm{CO}_{2}$ uptake that ultimately results in a reduction in plant growth. However, heat tolerance is highly variable among plant species, and thresholds can differ within species depending on the growth conditions and genotype of an individual (Sage and Kubien 2007).

Another important consequence of high temperatures for plants is a reduction of stomatal conductance. Plants elevate 
their transpiration rates when leaf temperature reaches critical ranges, and water becomes a limiting factor for photosynthesis (Anderson 1982), then close their stomata in response to elevated transpiration rates and reduced leaf water potential, as a consequence of the development of high levels of vapor pressure deficit (VPD) (Bassow and Bazzaz 1998; Kholová et al. 2010). All these effects reduce $\mathrm{CO}_{2}$ assimilation and photosynthesis (Lloyd and Farquhar 2008). Thus, high temperatures overall decrease both $\mathrm{CO}_{2}$ assimilation rates and water use efficiency (WUE) (Miller-Rushing et al. 2009). Internal carbon concentration $\left(C_{i}\right)$ can indirectly influence photosynthesis, because stomata control the influx of $\mathrm{CO}_{2}$ to the plant. This influx is dependent on the existing $\mathrm{CO}_{2}$ concentration inside the plant, which also increases with high temperatures. A higher photosynthesis will also depend on the regeneration of Rubisco substrate and on the enzyme itself, which are also sensitive to high temperatures (Berry and Björkman 1980).

In a larger context, the consequences of these changes in plant ecophysiology are alterations of the carbon cycle and the stability of an ecosystem, by affecting net photosynthesis and plant respiration (Clark et al. 2003). Our immediate goal was to compare the leaf gas exchange parameters of two common tropical trees belonging to two contrasting ecological preferences and growing in similar and natural conditions within the low-land rainy forest and how these gas exchange traits were affected by sudden changes in leaf temperature. Measuring temperature effects on leaf photosynthesis will improve our ability to predict how photosynthetic $\mathrm{CO}_{2}$ uptake will respond to variation in diurnal temperature cycles with future climatic changes (Bernacchi et al. 2001). However, the knowledge about these specific changes in the physiological responses to temperature by tropical trees is still needed.

As mentioned above, temperature thresholds of plants could vary in response to the growth conditions and the genotype of an individual. Temperature may affect $\mathrm{CO}_{2}$ assimilation, even in a tropical rainforest where plant species grow in a warm environment. In this study, we describe the effect of instantaneous temperature changes on the photosynthetic processes. Also, we associate functional traits at a leaf-level with the ecological requirements of tree species to explain responses to instantaneous temperature changes. With this information, we can predict the behavior of tropical rainforest tree species in the near future with respect to sudden increases in ambient temperature, as an approximation for future tree responses to global change.

\section{Methods}

Study site and plant species

La Selva Biological Station is located in the Costa Rican Caribbean region next to Braulio Carrillo National Park $\left(10^{\circ} 26^{\prime} \mathrm{N}, 83^{\circ} 59^{\prime} \mathrm{W}\right)$. This study was done on trees of the early successional species Zygia longifolia (Fabaceae) that were growing next to the Puerto Viejo river bank between the Stone Bridge and the beginning of the Arriera-Zompopa trail, on a 1- to 12-year secondary forest (La Selva GIS map 2012). Z. longifolia is generally a riparian species but can grow in any soil opportunistically (Ardón et al. 2009; Camacho et al. 2009). We also studied several planted trees of the late successional species Dipteryx oleifera (Fabaceae) that were growing at the entrance of the station, and surrounded by tree plantations and other secondary succession vegetation. D. oleifera is an emergent old growth forest tree, which requires light gaps to develop and reach adult size (Clark and Clark 1987). In both cases, lower and mid canopy branches of young trees were carefully pulled by ropes in order to get distal shoots that were naturally exposed to almost completely open sky, resembling typical open canopy microclimatic conditions of the natural forest canopy.

\section{Morphological traits}

These traits were measured in five leaves per morphological characteristic of each of the five trees per species in the same or in a neighbor leaflet: specific leaf area (SLA) according to Garnier et al. (2001), by measuring the area in an area section without main veins and posterior drying in an oven for $72 \mathrm{~h}$; leaf thickness (LT) was measured with a micrometer (C) Mitotuyo America Corporation, USA) according to Castro-Díez et al. (1997); stomatal ratio and stomatal density were calculated from leaf impressions made with a commercial and transparent nail polish.

\section{Gas exchange measurements}

We measured leaf level gas exchange parameters from three different sets of data: from assimilation to internal carbon concentration curves $\left(A C_{i}\right.$ curves) at two-leaf temperatures, from assimilation to light response curves (light curves) and from maximum assimilation measurements along a gradient of leaf temperature values. All measurements were performed with one of the two gas exchange systems available: an LCpro + portable photosynthesis system (ADC Bioscientific Ltd.), and an LI-6400XT portable photosynthesis system (LI-COR, Inc. Lincoln, NE, USA). Both IRGAs were calibrated according to standard parameters (flux rate, zero $\mathrm{CO}_{2}$ and $\mathrm{H}_{2} \mathrm{O}$ ) on a daily basis and using fresh soda lime and desiccant.

$A C_{i}$ response curves

These curves were generated for a leaf on each of five trees per species at $27^{\circ} \mathrm{C}$ (approximately mean daily 
temperature) and at a constant photosynthetic photon flux density (PPFD) of $1,000 \mu \mathrm{mol} \mathrm{m}{ }^{-2} \mathrm{~s}^{-1}$. External $\mathrm{CO}_{2}$ concentrations $\left(C_{a}\right)$ were adjusted automatically in the following order: 400, 300, 200, 100, 50, 400, 500, 700, $900 \mathrm{ppm}$. At each step, there was an acclimation period of 5 min before recording gas exchange data, following the guidelines proposed by Warren and Dreyer (2006). $A C_{i}$ response curves were analyzed using the mathematical model developed by Sharkey et al. (2007) and the data were automatically fitted with the model fitting utility based on a Microsoft Excel program (Downloaded at http:// www.blackwellpublishing.com/plantsci/pccalcuçation/).

This free available program uses a series of three equations to obtain some physiological traits of the plants described below. The portion of the entire $A C_{i}$ curve when the $\mathrm{CO}_{2}$ net assimilation $(A)$ is Rubisco-limited is described by the following equation:

$A=V_{\mathrm{c}, \max }\left[\frac{C_{\mathrm{c}}-I^{*}}{C_{\mathrm{c}}+K_{\mathrm{C}}\left(1+O / K_{\mathrm{O}}\right)}\right]-R_{n}$

where $V_{c, \max }$ is the maximum velocity of RuBP saturation rate of carboxylation, $C_{\mathrm{c}}$ is the $\mathrm{CO}_{2}$ partial pressure, $K_{\mathrm{c}}$ is the Michaelis constant of Rubisco for $\mathrm{CO}_{2}, O$ is the partial pressure of oxygen, $K_{\mathrm{o}}$ is the Michaelis constant of Rubisco for $\mathrm{O}_{2}$ and $R_{n}$ is the mitochondrial respiration. The portion of the $A C_{i}$ curve when $A$ is limited by RuBP regeneration is performed by running the equation:

$A=J \frac{C_{\mathrm{c}}-I^{*}}{4 C_{\mathrm{c}}+8 I^{*}}-R_{n}$

where $J$ is the rate of electron transport. This equation assumes four electrons per carboxylation and oxygenation. Finally, the fitting utility runs the last equation that the models require, when $A$ is limited by the amount of triose phosphate utilization (TPU):

$A=3 \mathrm{TPU}-R_{n}$

where TPU is the rate of use of triose-phosphates but can also be any export of carbon from the Calvin cycle.

Leaf photosynthetic responses to temperature

This type of response was studied first by making light response curves at two different leaf temperatures. These were also measured to determine minimum PPFD values to reach saturating assimilation rates and to obtain the photosynthetic parameters with respect to light for both species. Light curves were constructed at 27 and $37{ }^{\circ} \mathrm{C}$ at 12 different light radiation levels between 1,600 and $0 \mu \mathrm{mol} \mathrm{m}{ }^{-2} \mathrm{~s}^{-1}$, using a preset flow of 270 (U) which allowed us to control easily relative humidity and kept it above $60 \%$. We analyzed this set of data following the empirical model suggested by:
$A=A_{\max }\left[1-\mathrm{e}^{-\emptyset\left(I-I_{\mathrm{c}}\right)}\right]$

where $A$ is $\mathrm{CO}_{2}$ assimilation, $I$ is irradiance, $I_{\mathrm{c}}$ is light compensation point, $\varnothing$ describes the shape of the equation and $A_{\max }$ is $\mathrm{CO}_{2}$ light-saturated assimilation. We obtained the apparent quantum yield $\left(Q_{\mathrm{app}}\right)$ and dark respiration $\left(R_{\mathrm{d}}\right)$ from the slope and the intersection with the $y$ axis of the linear regression obtained from six PPFD values between 0 and $100 \mu \mathrm{mol} \mathrm{m}{ }^{-2} \mathrm{~s}^{-1}$, respectively. The light compensation point $\left(I_{\mathrm{c}}\right)$ was interpolated as the intersection with the $x$ axis.

To study the effect of temperature changes on plant physiology, we generated temperature response curves by measuring $\mathrm{CO}_{2}$ net assimilation in response to eight leaf temperatures, ranging between 20 and $45^{\circ} \mathrm{C}$. We created one temperature response curve per leaf in five individuals per species. During the measurements, VPD was controlled through variation of the flow rate towards the desiccation tube. The vapor pressure deficit values for both species were maintained below $2 \mathrm{Kpa}$, to keep stomatal conductance above $0.05 \mathrm{mmol} \mathrm{m}^{-2} \mathrm{~s}^{-1}$, avoiding indirect effects on the photosynthetic responses as indicated by Bernacchi et al. (2001). Subtle changes in the flow rate also allowed us to keep the balance between temperature, relative humidity values and changes in VPD.

Temperature response curves were analyzed according to Cavieres et al. (2000), by fitting the data to a second order polynomial function to obtain the three parameters: optimum temperature for photosynthesis, which is calculated through the first derivative of the polynomial curves; the low and high temperature compensation points (HTCP and LTCP, respectively), as the temperatures at which leaf carbon balance becomes zero, by solving the polynomial equations.

Data analysis

The morphological variables and the parameters derived from the $A C_{i}$ curves and light response curves were compared between species performing a Mann-Whitney $U$ test executed on the statistical software STATISTICA 8 (StatSoft, Inc., OK, USA). The parameters obtained from the temperature-response polynomial functions were compared between species performing $t$ test for independent samples analysis, in STATISTICA 8 (StatSoft, Inc., OK, USA).

\section{Results}

Morphological traits

Two out of three leaf morphological traits were significantly different between our two tree species. D. oleifera and Z. longifolia showed no significant differences in SLA 
(Table 1), but significant differences in the LT, where $Z$. longifolia showed thinner (36\%) leaves than D. oleifera (Table 1). Leaves of both species are hypostomatic and there was a higher $(25 \%)$ stomatal density on Z. longifolia (Table 1).

\section{Physiological measurements}

\section{Assimilation/internal carbon curves}

$A C_{i}$ response curves showed that when the $\mathrm{CO}_{2}$ rises, the photosynthesis increases but the maximum photosynthetic rate under saturating $\mathrm{CO}_{2}$ was significantly different between species $\left(A_{\max }\right.$, Table 2$)$ with $Z$. longifolia showing a $(23 \%)$ higher $\mathrm{CO}_{2}$ assimilation rate than D. oleifera. The mitochondrial respiration of both species did not show significant differences $\left(R_{n}\right.$, Table 2). Maximum RuBP saturation rate of carboxylation $\left(V_{\mathrm{C}}, \max\right.$, Table 2$)$ was $(13 \%)$ lower in D. oleifera. A great intraspecific variation on the rate of photosynthetic electron transport produced a no significant difference for this parameter ( $J$, Table 2), and the rate of triose-phosphate utilization was very similar between our two species (TPU, Table 2). The $\mathrm{CO}_{2}$ compensation point was another parameter that showed very high variation, mostly on $D$. oleifera, and no significant difference found between species ( $I^{*}$, Table 2$)$.

\section{Photosynthesis responses to irradiance}

The light response curves of both species measured under natural climatic conditions showed a significant difference between species on their maximum photosynthetic rate and respiration rate $\left(A_{\max }\right.$ and $\left.R_{\mathrm{d}}\right)$. In those variables, Z. longifolia showed a $22 \%$ higher $A_{\max }$ than D. oleifera. On the other hand, D. oleifera had $60 \%$ higher $R_{d}$. We found no significant differences between species in the stomatal conductance $\left(g_{s}\right)$, transpiration rate $(E)$, WUE at saturating light conditions, and also no differences in apparent quantum yield $\left(Q_{\text {app }}\right)$ and light compensation point $\left(I_{\mathrm{c}}\right)$. The parameters obtained of the mathematical model showed a similar pattern where $A_{\max }$ of the model was significantly different between species ( $A_{\max }$ model); $Z$. longifolia presented a higher $(23 \%)$ photosynthetic rate. The shape of the curve $(\varnothing)$ and the light compensation point $\left(I_{\mathrm{c}}\right)$ were not significantly different between species (Table 3; Fig. 1).

We found important differences in the parameters obtained from the light-response curves between temperatures and species, when a thermal stress was applied during the measurements (Table 3; Fig. 1). At $37{ }^{\circ} \mathrm{C}$, there was $20 \%$ reduction of the $A_{\max }$ in $Z$. longifolia, but $D$. oleifera did not show significant differences. The $R_{d}$ of both species increases when exposed to a high temperature condition,

Table 1 Arithmetic mean $( \pm \mathrm{SD})$ of the morphological parameters measured on five leaves of each five individuals of Dipteryx oleifera and Zygia longifolia at La Selva Biological Station, Sarapiquí, Heredia, Costa Rica

\begin{tabular}{lccc}
\hline Parameter & Z. longifolia & D. oleifera & $P$ value \\
\hline SLA $\left(\mathrm{gm}^{-2}\right)$ & $123.71(10.91)$ & $128.58(21.97)$ & N.S. \\
LT $(\mathrm{mm})$ & $0.156(0.011)$ & $0.241(0.025)$ & $*$ \\
SD $\left(\# / \mathrm{mm}^{-2}\right)$ & $351.68(49.42)$ & $263.68(22.21)$ & $*$ \\
\hline
\end{tabular}

$S L A$ specific leaf area, $L T$ leaf thickness, $S D$ stomatal density

Mann-Whitney $U$ test results: significant differences at $P<0.001(*)$

N.S. non-significant

Table 2 Arithmetic mean $( \pm \mathrm{SD})$ of the photosynthetic parameters obtained from the $A_{\mathrm{C} i}$ response curves of five individuals of Dipteryx oleifera and Zygia longifolia at La Selva Biological Station, Sarapiquí, Heredia, Costa Rica

\begin{tabular}{lcccc}
\hline Parameter & Z. longifolia & D. oleifera & $P$ value \\
\hline$A_{\max }\left(\mu \mathrm{mol} \mathrm{CO} \mathrm{m}^{-2} \mathrm{~s}^{-1}\right)$ & $14.80(2.97)$ & $11.45(1.97)$ & $*$ \\
$R_{n}\left(\mu \mathrm{mo} \mathrm{CO}_{2} \mathrm{~lm}^{-2} \mathrm{~s}^{-1}\right)$ & $-1.58(0.31)$ & $-2.05(0.62)$ & \\
$V_{\mathrm{C}, \max }\left(\mu \mathrm{mol} \mathrm{m}^{-2} \mathrm{~s}^{-1}\right)$ & $72.64(5.76)$ & $62.93(8.19)$ & \\
$J\left(\mu \mathrm{mol} \mathrm{m} \mathrm{s}^{-1}\right)$ & $84.81(13.44)$ & $72.03(8.81)$ & \\
TPU & $5.25(0.92)$ & $4.36(0.65)$ & N.S. \\
$I^{*}(\mathrm{ppm})$ & $56.57(3.98)$ & $65.76(8.88)$ & N.S. \\
\hline
\end{tabular}

Maximum photosynthetic rate $\left(A_{\max }\right)$, mitochondrial respiration $\left(R_{n}\right)$, maximum RuBP saturation rate of carboxylation $\left(V_{\mathrm{C}, \max }\right)$, rate of photosynthetic electron transport $(J)$, rate of triose phosphate utilization (TPU) and $\mathrm{CO}_{2}$ compensation point in absence of dark respiration $\left(I^{*}\right)$ where obtained from fitting equation utility (Sharkey et al. 2007). Mann-Whitney $U$ test results: significant differences at $P<0.05(*)$

N.S. non-significant 
Table 3 Arithmetic mean $( \pm \mathrm{SD})$ of the leaf photosynthetic parameters obtained from the light response curves of five individuals of Dipteryx oleifera and

Zygialongifolia at La Selva

Biological Station, Sarapiquí, Heredia, Costa Rica

\begin{tabular}{|c|c|c|c|c|}
\hline Parameter & Temperature $\left({ }^{\circ} \mathrm{C}\right)$ & Z. longifolia & D. oleifera & $P$ value \\
\hline \multirow[t]{3}{*}{$A_{\max }\left(\mu \mathrm{mol} \mathrm{CO} \mathrm{m}^{-2} \mathrm{~s}^{-1}\right)$} & 27 & $16.58(1.23)$ & $12.91(1.95)$ & $*$ \\
\hline & 37 & $13.32(1.70)$ & $10.24(2.95)$ & $*$ \\
\hline & $P$ value & $*$ & N.S. & \\
\hline \multirow[t]{3}{*}{$R_{\mathrm{d}}\left(\mu \mathrm{mol} \mathrm{CO} \mathrm{Cm}^{-2} \mathrm{~s}^{-1}\right)$} & 27 & $-0.22(0.17)$ & $-0.55(0.20)$ & $*$ \\
\hline & 37 & $-0.92(0.24)$ & $-1.13(0.39)$ & N.S. \\
\hline & $P$ value & $* *$ & $* *$ & \\
\hline \multirow[t]{3}{*}{$g_{\mathrm{s}}\left(\mathrm{mol} \mathrm{m}{ }^{-2} \mathrm{~s}^{-1}\right)$} & 27 & $0.52(0.10)$ & $0.35(0.16)$ & N.S. \\
\hline & 37 & $0.49(0.48)$ & $0.18(0.08)$ & $*$ \\
\hline & $P$ value & N.S. & $*$ & \\
\hline \multirow[t]{3}{*}{$E\left(\mathrm{mmol} \mathrm{H} \mathrm{H}_{2} \mathrm{~m}^{-2} \mathrm{~s}^{-1}\right)$} & 27 & $5.79(1.06)$ & $3.72(1.55)$ & N.S. \\
\hline & 37 & $9.73(2.10)$ & $4.40(1.82)$ & $*$ \\
\hline & $P$ value & $* *$ & N.S. & \\
\hline \multirow[t]{3}{*}{ WUE $\left(\mu \mathrm{mol} \mathrm{CO} \mathrm{CO}_{2} \mathrm{mmol} \mathrm{H}_{2} \mathrm{O}\right)$} & 27 & $2.91(0.40)$ & $3.80(1.13)$ & N.S. \\
\hline & 37 & $1.41(0.28)$ & $2.45(0.51)$ & $* *$ \\
\hline & $P$ value & $* *$ & N.S. & \\
\hline \multirow[t]{3}{*}{$Q_{\text {app }}$} & 27 & $0.069(0.01)$ & $0.060(0.01)$ & N.S. \\
\hline & 37 & $0.055(0.01)$ & $0.044(0.01)$ & $*$ \\
\hline & $P$ value & $*$ & $*$ & \\
\hline \multirow[t]{3}{*}{$I_{\mathrm{c}}$} & 27 & $3.08(2.47)$ & $7.07(4.42)$ & N.S. \\
\hline & 37 & $16.39(3.02)$ & $25.42(6.76)$ & $*$ \\
\hline & $P$ value & $* *$ & $* *$ & \\
\hline \multirow[t]{3}{*}{$A_{\max }($ model $)$} & 27 & 16.75 (1.06) & $12.95(1.98)$ & $* *$ \\
\hline & 37 & $13.24(1.78)$ & $10.54(2.86)$ & N.S. \\
\hline & $P$ value & $*$ & N.S. & \\
\hline \multirow[t]{3}{*}{$\varnothing\left(10^{-3}\right)($ model $)$} & 27 & $49.67(2.47)$ & $52.48(11.25)$ & N.S. \\
\hline & 37 & $50.13(4.34)$ & $48.44(17.82)$ & N.S. \\
\hline & $P$ value & N.S. & N.S. & \\
\hline \multirow[t]{3}{*}{$I_{\mathrm{c}}($ model $)$} & 27 & $3.50(2.53)$ & $4.77(4.10)$ & N.S. \\
\hline & 37 & $15.53(2.90)$ & $23.10(6.97)$ & N.S. \\
\hline & $P$ value & $* *$ & $* *$ & \\
\hline
\end{tabular}

\section{Temperature-response curves}

Temperature-response curves showed that net $\mathrm{CO}_{2}$ assimilation was significantly reduced at the lower temperatures. Increasing temperatures concomitantly raised assimilation. In both species, the optimum temperature for the maximum photosynthesis rate was very similar, at approximately $28{ }^{\circ} \mathrm{C}$. From this point, a sustained decrease in assimilation was observed. At the highest temperature measured, we saw a 50 and $33 \%$ reduction in assimilation on D. oleifera and Z. longifolia, respectively. The LTCP value for D. oleifera was two and a half times higher than for $Z$. longifolia. The HTCP showed the same pattern where $Z$. longifolia showed a higher value $(8 \%)$. As shown before, Z. longifolia exhibited a higher photosynthetic rate than $D$. oleifera, and that difference was maintained at all temperature points (Table 4; Fig. 3). 
Fig. 1 Leaf photosynthetic parameters obtained from the light response curves of Dipteryx oleifera and Zygia longifolia. Maximum photosynthetic rate $\left(A_{\max }\right)$, respiration $\left(R_{\mathrm{d}}\right)$, stomatal conductance $\left(g_{\mathrm{s}}\right)$, transpiration rate $(E)$ and water use efficiency (WUE). Apparent quantum yield $\left(Q_{\text {app }}\right)$, light compensation point $\left(I_{\mathrm{c}}\right)$, obtained from the linear regression. $A_{\max }$, curvature $(\varnothing)$ and $I_{\mathrm{c}}$ were also obtained from a empiric mathematical model (Küppers and Schulze 1985). MannWhitney $U$ test: differences between treatments at $P<0.05(*), P<0.01(* *), N S$ no significant. Difference between species at $P<0.05(\mathrm{ab})$
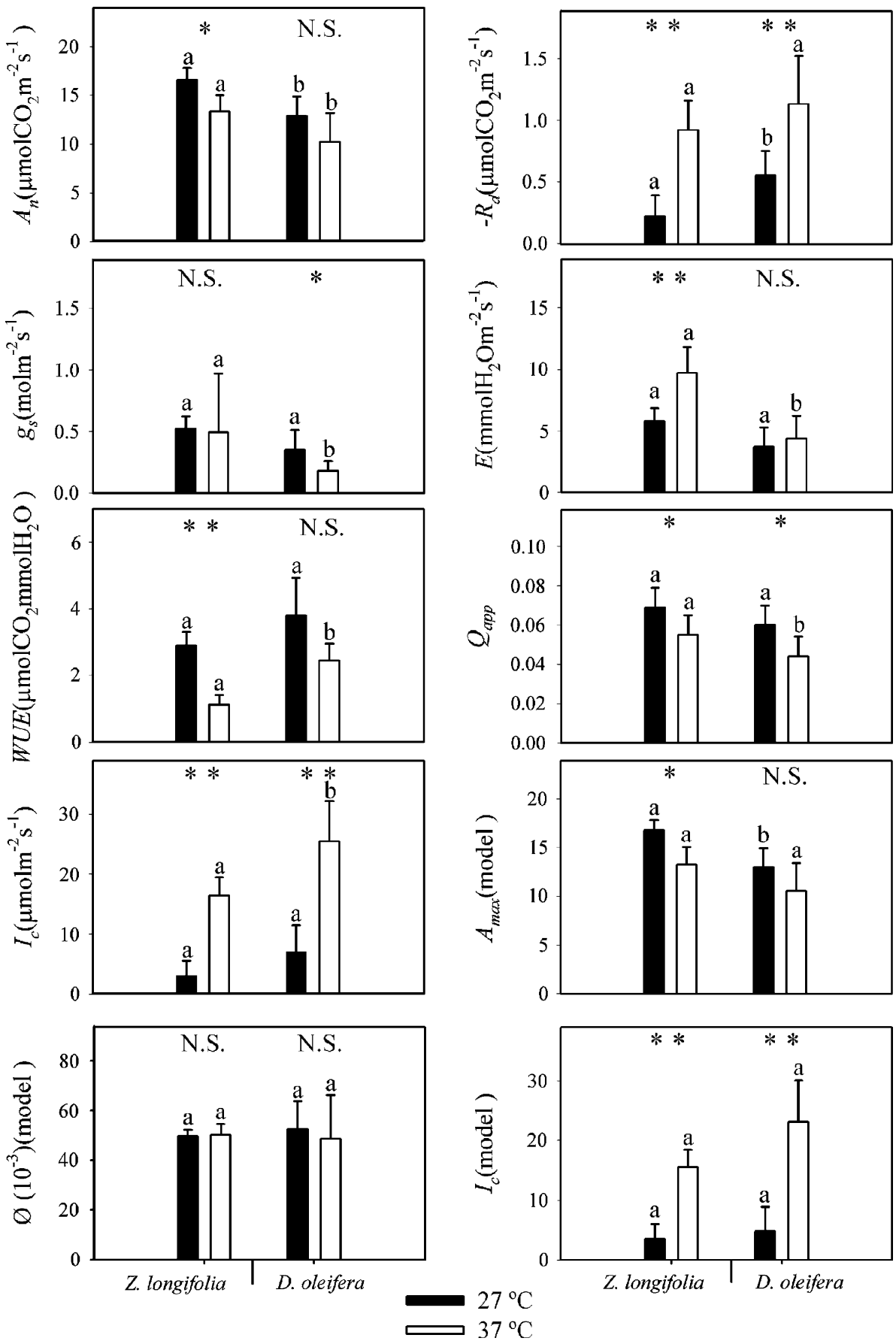

example, pioneer species increase the ratio of leaf area per unit plant mass along with the specific leaf area, due to strong competition for light in early succession habitats (Quilici and Medina 1998). However, we did not find any differences in SLA data between Z. longifolia and D. oleifera. It is well known that leaves of juvenile trees of $D$. oleifera may have a high phenotypic plasticity and can respond properly to the growing conditions (Fetcher et al. 1987). We expected that $D$. oleifera were adapting SLA in response to the growing conditions, in the same way that 
Fig. 2 Light response curves of photosynthesis obtained at two leaf temperatures from two tropical rain forest tree species at La Selva Biological Station, Sarapiquí, Heredia, Costa Rica. Each point represents the arithmetic mean $( \pm \mathrm{SD})$ of photosynthetic rate obtained from five trees

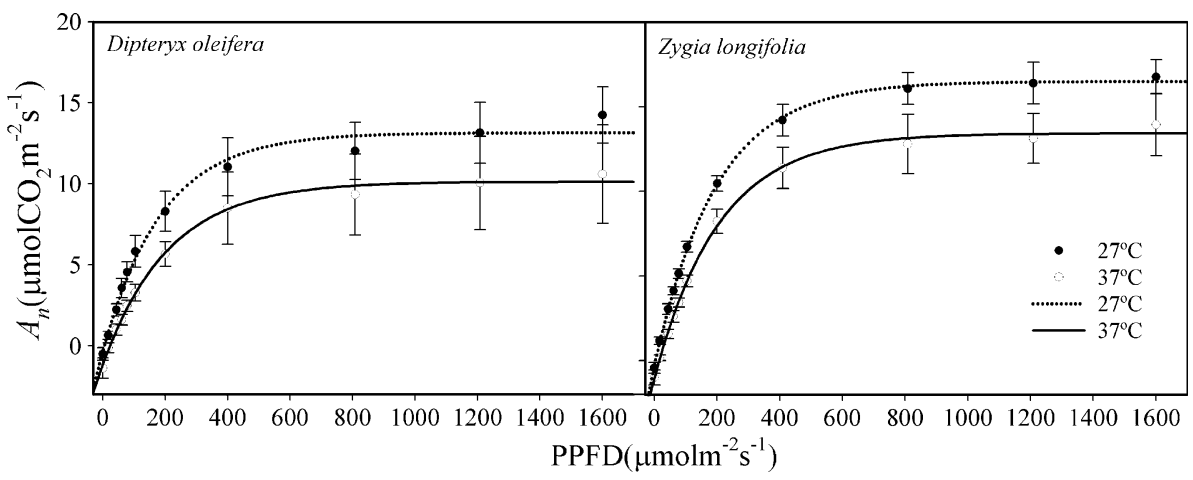

Table 4 Arithmetic mean $( \pm \mathrm{SD})$ of the optimum temperature for photosynthesis (Opt. T), low temperature (LTCP) and high temperature (HTCP) compensation points for Dipteryx oleifera and Zygia longifolia at La Selva Biological Station, Sarapiquí, Heredia, Costa Rica

\begin{tabular}{llcc}
\hline Species & Opt. T $\left({ }^{\circ} \mathrm{C}\right)$ & LTCP $\left({ }^{\circ} \mathrm{C}\right)$ & HTCP $\left({ }^{\circ} \mathrm{C}\right)$ \\
\hline D. oleifera & $28.80(2.09)$ & $10.00(2.28)$ & $47.61(2.65)$ \\
$Z$. longifolia & $27.92(1.13)$ & $4.08(2.88)$ & $51.75(1.34)$ \\
$P$ value & N.S. & $* *$ & $*$
\end{tabular}

Parameters obtained from second order polynomial equations derived of the nonlinear correlation analysis. $t$ test results: significant differences at $P<0.05(*), P<0.01(* *)$

N.S. no significant

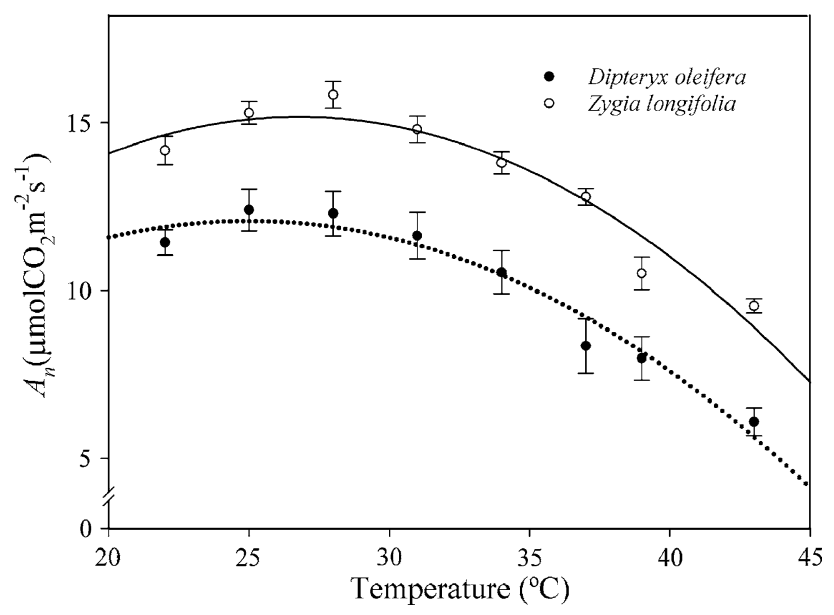

Fig. 3 Temperature response curves of leaf photosynthesis from two tropical rain forest tree species at La Selva Biological Station, Sarapiquí, Heredia, Costa Rica. Each point represents the arithmetic mean $( \pm \mathrm{SD})$ from five trees, the net $\mathrm{CO}_{2}$ assimilation $\left(A_{n}\right.$, $\mu \mathrm{mol} \mathrm{CO}_{2} \mathrm{~m}^{-2} \mathrm{~s}^{-1}$ ) in response to the different temperature values $\left({ }^{\circ} \mathrm{C}\right)$. Data fitted to a second order polynomial equation

their seedlings were able to respond to contrasting light conditions. Developing leaves with low SLA as typical of early successional trees do exploit light resources and develop in full light conditions (Valladares et al. 2002). Our two species had low SLA which is associated with open light conditions in the canopy for old successional tree species. However, some morphological and physiological adaptations of late successional species such as $D$. oleifera, which colonize gaps, are similar to adaptations found in early successional trees species such as Z. longifolia (García-Núñez et al. 1995). Although we did not find differences in SLA between the two plant species, we can identify differences between them based on other morphological traits. D. oleifera had thicker leaves (36\%), which is a morphological characteristic of late successional tree species (Bazzaz 1979). Leaf thickness plays an important role in leaf metabolism, and is highly related to the photosynthetic capacity of a leaf. LT is likely to affect the amount of light absorbed and the diffusion of $\mathrm{CO}_{2}$ (Vile et al. 2005). Such morphological adaptations developed in response to saturating light conditions (Nobel et al. 1975), and allow a plant optimally use nutrients, water and light (Valladares et al. 2002).

We found that both species have hypostomatic leaves as previously found for D. oleifera and similar species (Fetcher et al. 1983). Hypostomatic leaves are common in tropical rainforest trees (Camargo and Marenco 2011), and probably this trait is especially important for canopy leaves, which are directly exposed to the more drastic micro-environmental conditions (Chen et al. 1999). In the same sense, higher stomatal densities have been clearly associated with tropical canopy leaves (Camargo and Marenco 2011). In our case, stomatal density differed between the two species such that, Z. longifolia had $25 \%$ more stomata per leaf area than $D$. oleifera. Given the fact that stomatal density is related to the ecological preferences of plant species (Sellin et al. 2010), we expected to find 
more stomata on Z. longifolia species that is generally associated with riparian habitats, where there are no limitations on water as a resource (Ardón et al. 2009).

\section{Physiological measurements}

When we measured the response of maximum photosynthetic rate to both internal carbon concentrations and to light for D. oleifera, we found that it was approximately $22 \%$ lower than $Z$. longifolia. Thus, a higher LT value seems to relate negatively with photosynthesis. Previous research has shown that thicker leaves have reduced photosynthesis, because at saturating irradiance, photosynthesis is mostly limited by the rate of $\mathrm{CO}_{2}$ diffusion (Longstreth and Nobel 1979), and because the $\mathrm{CO}_{2}$ diffusion through the leaf tissue depends on the amount of air space inside the leaf and the internal tissue conductance (Nobel 1977), a larger spongy mesophyll area or volume actually occurs in D. oleifera. Some studies have shown that plants with thicker leaves, large amounts of mesophyll, and big air space have higher levels of photosynthesis (Garnier et al. 1999). However, this relationship seems to apply only to plants with stomata on both sides of the leaves (Fetcher et al. 1983). Nevertheless, high photosynthetic rates are a physiological adaptation common to early succession plant species (Bazzaz 1979; Huc et al. 1994), clearly supporting the ecological preference of our $Z$. longifolia.

Internal conductance limits photosynthesis and has a large effect on the $V_{\mathrm{C}, \max }$ (Warren and Dreyer 2006). We observed that $Z$. longifolia have a higher maximum RuBP rate of carboxylation than $D$. oleifera. An elevated internal tissue conductance results in a higher $V_{\mathrm{C}, \max }$ and consequently a superior maximum photosynthetic rate. In addition, this difference is in agreement with its previously discussed thinner leaves.

Stomatal conductance also plays an important role in photosynthesis via $\mathrm{CO}_{2}$ uptake and control of the water loss (Lammertsma et al. 2011). Plant species with the highest stomatal conductance are going to be expected to have a higher maximum $\mathrm{CO}_{2}$ assimilation (Messinger et al. 2006). Although we did not find a significant difference between the two species studied, Z. longifolia always showed a higher stomatal conductance and transpiration rate. According to other studies, plants with an elevated maximum photosynthetic rate have higher stomatal conductance values and lower WUE (Marenco et al. 2001). We did not find significant differences between our species apparent quantum yield and light compensation point. The values we obtained for those parameters were similar to values in other studies of trees with high photosynthetic efficiency. Although our individuals were located in high light conditions, responses to light were similar to previous studies of seedlings exposed to low light growth conditions; they exhibited high apparent quantum yield and low light compensation points (Jiang et al. 2002).

Plant responses to temperature agree with many previous studies in which high temperatures reduced $\mathrm{CO}_{2}$ net assimilation (Frolec et al. 2008). When we measured the photosynthetic responses to light during temperature stress, the maximum photosynthetic rate was lower than without temperature stress. Although we did not see a significant difference in D. oleifera, we did observe high intraspecific variation which indicates that individuals may have different responses depending on the growing condition and genotype (Wang et al. 2008). However, the decline in photosynthesis was significant for Z. longifolia.

A reduction in maximum $\mathrm{CO}_{2}$ assimilation rate cannot explain complete photosynthetic responses to temperature, because the plant responses involve more complex processes. Photosynthesis is the result of a combination of many physiological processes, and it is likely that many indirect effects also explain the observed response to temperature (Berry and Björkman 1980). Photosynthesis is highly dependent on stomatal conductance, and stomatal conductance of D. oleifera declined $49 \%$ during temperature stress. This decline helped to stabilize the leaf water balance more effectively than in Z. longifolia, as evidenced by a much higher transpiration in $Z$. longifolia in which stomatal conductance decreased only $6 \%$. Other studies on tropical late successional trees have suggested that low stomatal conductance maintains stability in tree water balance (Carswell et al. 2000). Also, species with lower photosynthetic rate capacity tend to show higher WUE (Santiago et al. 2004). The opposite response is common in early succession trees such as Z. longifolia (Silva et al. 2011). Responses of $Z$. longifolia may also be related to its riparian habitat (Tsialtas et al. 2001). Despite there were some important increases in VPD values corresponding with increases in temperature, they did not resulted in a concomitant reduction in stomatal conductance. This fact supports our experiment by saying that there were no indirect effects of temperature on the observed reduction of assimilation.

Another physiological characteristic affected by the high temperature was $Q_{\text {app. }}$. In $D$. oleifera, this characteristic decreased $27 \%$ along with the increment of the light compensation point. This goes according to the lower rate of RuBP carboxylation which affects directly the $Q_{\text {app }}$ (Timm et al. 2002). Low $V_{\mathrm{C}, \max }$ may affect response to temperature by reducing the $Q_{\text {app }}$ and increasing light compensation point. Both changes were also observed and significant in Z. longifolia, but were larger in D. oleifera. Thus, early successional tree species may have more capability to acclimate their metabolism to high temperatures. 
Both species responded negatively to instantaneous temperature changes. However, the narrower interval between the high and low temperature compensation points of D. oleifera support previous work showing that early successional tree species are better able than late successional species to adjust to variation and stressful conditions such as an instantaneous rise in temperature (Bazzaz and Carlson 1982). Early successional plant species developed in a more variable ambient, with typically higher temperature fluctuations, contrary to the situation in later successional forest vegetation, where variation in temperature, wind and moisture are less fluctuating (Bazzaz 1979).

It is well known that many plant physiological characteristics can be linked to functions that influence such ecosystem processes (Sandquist and Cordell 2007). Overall, we found that plant function is affected by high temperatures, where early succession tree species are likely to reduce their WUE and late succession tree species tend to increment their metabolic rates increasing the respiration and light compensation point.

Acknowledgments We would like to thank the CRUSA foundation for our participation in the Research Experience for Undergraduates Program (REU) through the Organization for Tropical Studies. Gas exchange systems were funded by two research grants from the Fondo Especial para la Educación Superior (FEES), Consejo Nacional de Rectores (CONARE), to the Biology and Agrarian Schools at UNA, Costa Rica. We thank MINAET, Jose A. Guzmán, Adrián Rodriguez, Diego Dierick, Jennifer Stynoski, Carola Scholz, Pedro González, Dori Thompson for their support during the different steps of this work.

\section{References}

Anderson JE (1982) Factors controlling transpiration and photosynthesis in Tamarix chinensis Lour. Ecology 63(1):48-56

Ardón M, Pringle CM, Eggert SL (2009) Does leaf chemistry differentially affect breakdown in tropical vs temperate streams? Importance of standardized analytical techniques to measure leaf chemistry. J N Am Benthol Soc 28(2):440-453

Bassow SL, Bazzaz FA (1998) How environmental conditions affect canopy leaf-level photosynthesis in four deciduous tree species. Ecology 79(8):2660-2675

Bazzaz FA (1979) The physiological ecology of plant succession. Ann Rev Ecol Syst 10:351-371

Bazzaz FA, Carlson RW (1982) Photosynthetic acclimation to variability in the light environment of early and late successional plants. Oecologia 54(3):313-316

Bernacchi CJ, Singsaas EL, Pimentel C, Portis AR, Long SP (2001) Improved temperature response functions for models Rubiscolimited photosynthesis. Plant Cell Environ 24:253-259

Berry J, Björkman O (1980) Photosynthetic response and adaptation to temperature in higher plants. Ann Rev Plant Physiol 31:491-543

Bonan G (2008) Forests and climate change: forcings, feedbacks, and the climate benefits of forests. Science 320:1444-1449

Camacho R, Boyero L, Cornejo A, Ibáñez A, Pearson RG (2009) Local variation in shredder distribution can explain their oversight in tropical streams. Biotropica 41(5):625-632
Camargo MA, Marenco RA (2011) Density, size and distribution of stomata in 35 rainforest tree species in Central Amazonia. Acta Amazonica 41(2):205-212

Carswell FE, Meir P, Wandelli EV, Bonates LC, Kruijt B, Barbosa EM, Jarvis PG (2000) Photosynthetic capacity in a central Amazonian rain forest. Tree Physiol 20:179-186

Castro-Díez P, Villar-Salvador P, Pérez-Rontomé C, Maestro-Martínez M, Montserrat-Martí G (1997) Leaf morphology and leaf chemical composition in three Quercus (Fagaceae) species along a rainfall gradient in NE Spain. Trees 11:127-134

Cavieres LA, Rada F, Azócar A, García-Núñez C, Cabrera HM (2000) Gas exchange and low temperature resistance in two tropical high mountain tree species from the Venezuelan Andes. Acta Oecol 21(3):203-211

Chen J, Saunders SC, Crow TR, Naiman RJ, Brosofske KD, Mroz GD, Franklin JF (1999) Microclimate in forest ecosystem and landscape ecology. Bioscience 49(4):288-297

Clark DA (2004) Sources or sinks? The responses of tropical forests to current and future climate and atmospheric composition. Phil Trans R Soc Lond B 359:477-491

Clark DB, Clark DA (1987) Population ecology and microhabitat distribution dipteryx panamensis a neotropical rain forest emergent tree. Biotropica 19(3):236-244

Clark DA, Piper SC, Keeling CD, Clark DB (2003) Tropical rain forest tree growth and atmospheric carbon dynamics linked to interannual temperature variation during 1984-2000. PNAS 100(10):5852-5857

Fetcher N, Strain BR, Oberbauer SF (1983) Effects of light regime on the growth, leaf morphology, and water relation of seedlings of two species of tropical trees. Oecologia 58:314-319

Fetcher N, Oberbauer SF, Rojas G, Strain BR (1987) Efectos del régimen de luz sobre la fotosíntesis y el crecimiento en plántulas de árboles de un bosque lluvioso tropical de Costa Rica. Rev Biol Trop 35(1):97-110

Frolec J, Ilík P, Krchnák P, Susila P, Naus J (2008) Irreversible changes in barley leaf chlorophyll fluorescence detected by the fluorescence temperature curve in a linear heating/cooling regime. Photosynthetica 46(4):537-546

García-Núñez C, Azócar A, Rada F (1995) Photosynthetic acclimation to light in juveniles of two cloud forest tree species. Trees 10:114-124

Garnier E, Salager J-L, Laurent G, Sonié L (1999) Relationships between photosynthesis, nitrogen and leaf structure in 14 grass species and their dependence on the basis of expression. New Phytol 143:119-129

Garnier E, Shipley B, Roumet C, Laurent G (2001) A standardized protocol for the determination of specific leaf area and laef dry matter content. Funct Ecol 15:688-695

Huc R, Ferhi A, Guehl JM (1994) Pioneer and late stage tropical rainforest tree species (French Guiana) growing under common conditions differ in leaf gas exchange regulation, carbon isotope discrimination and leaf water potential. Oecologia 99:297-305

Jiang H, Wang X-H, Deng Q-Y, Yuan L-P, Xu D-Q (2002) Comparison of some photosynthetic characters between two hybrid rice combinations differing in yield potential. Photosynthetica 40(1):133-137

Kholová J, Hash CT, Kumar PL, Yadav RS, Kocova M, Vadez V (2010) Terminal drought-tolerant pearl millet [Pennisetum glaucum (L.) R. Br.] have high leaf ABA and limit transpiration at high vapour pressure deficit. J Exp Bot 61(5):1431-1440

Küppers M, Schulze ED (1985) An empirical model of net photosynthesis and leaf conductance for the simulation of diurnal courses of $\mathrm{CO}_{2}$ and $\mathrm{H}_{2} \mathrm{O}$ exchange. Funct Plant Biol 12(5):513-526

Kurek I, Chang TK, Bertain SM, Madrigal A, Lui L, Lassner MW, Zhu G (2007) Enhanced thermostability of arabidopsis rubisco 
activase improves photosynthesis and growth rates under moderate heat stress. Plant Cell 19:3230-3241

Lammertsma EI, de Boer HJ, Dekker SC, Dilcher DL, Lotter AF, Wagner-Cremer F (2011) Global $\mathrm{CO}_{2}$ rise leads to reduced maximum stomatal conductance in Florida vegetation. PNAS 108(10):4035-4040

Li Y, Xu W, Wang J, Xing D (2011) Study on the relationship between delayed fluorescence and photosynthetic capability at elevated temperature in higher plants. J Phys Conf Ser 277:1-6

Lloyd J, Farquhar GD (2008) Effects of rising temperatures and $\left[\mathrm{CO}_{2}\right]$ on the physiology of tropical forest trees. Phil Trans R Soc B 363:1811-1817

Longstreth DJ, Nobel PS (1979) Salinity effects on leaf anatomy. Plant Physiol 63:700-703

Marenco RA, Goncalves JF, Vieira G (2001) Leaf gas exchange and carbohydrates in tropical trees differing in successional status in two light environments in central Amazonia. Tree Physiol 21:1311-1318

Messinger SM, Buckley TN, Mott KA (2006) Evidence for involvement of photosynthetic processes in the stomatal response to $\mathrm{CO}_{2}$. Plant Physiol 140:771-778

Miller-Rushing AJ, Primack RB, Templer PH, Rathbone S, Mukunda $\mathrm{S}$ (2009) Long-term relationships among atmospheric $\mathrm{CO}_{2}$, stomata, and intrinsic water use efficiency in individual trees. Am J Bot 96(10):1779-1786

Nobel PS (1977) Internal leaf area and cellular $\mathrm{CO}_{2}$ resistance: photosynthetic implications of variations with growth conditions and plant species. Physiol Plantarum 40(2):137-144

Nobel PS, Zaragoza LJ, Smith WK (1975) Relation between mesophyll surface area, photosynthetic rate, and illumination level during development for leaves of plectranthus parviflorus henckel. Plant Physiol 55:1067-1070

Quilici A, Medina E (1998) Photosynthesis-nitrogen relationships in pioneer plants of disturbed tropical montane forest sites. Photosynthetica 35(4):525-534

Sage RF, Kubien DS (2007) The temperature response of C3 and C4 photosynthesis. Plant, Cell Environ 30:1086-1106

Sandquist DR, Cordell S (2007) Functional diversity of carbon-gain, water-use, and leaf-allocation traits in trees of a threatened lowland dry forest in Hawaii. Am J Bot 94(9):1459-1469

Santiago LS, Goldstein G, Meinzer FC, Fisher JB, Machado K, Woodruff D, Jones T (2004) Leaf photosynthetic traits scale with hydraulic conductivity and wood density in Panamanian forest canopy trees. Oecologia 140:543-550

Sellin A, Eensalu E, Niglas A (2010) Is distribution of hydraulic constraints within tree crowns reflected in photosynthetic wateruse efficiency? An example of Betula pendula. Ecol Res $25: 173-183$

Sharkey TD (2005) Effects of moderate heat stress on photosynthesis: importance of thylakoid reactions, rubisco deactivation, reactive oxygen species, and thermotolerance provided by isoprene. Plant Cell Environ 28:269-277

Sharkey TD, Bernacchi CJ, Farquhar GD, Singsaas EL (2007) Fitting photosynthetic carbon dioxide response curves for C3 leaves. Plant Cell Environ 30:1035-1040

Silva CE, Goncales JF, Alves EG (2011) Photosynthetic traits and water use of tree species growing on abandoned pasture in different periods of precipitation in Amazonia. Photosynthetica 49(2):246-252

Timm HC, Stegemann J, Küppers M (2002) Photosynthetic induction strongly affects the light compensation point of net photosynthesis and coincidentally the apparent quantum yield. Trees $16: 47-62$

Tsialtas JT, Handley LL, Kassioumi MT, Veresoglou DS, Gagianas AA (2001) Interspecific variation in potential water-use efficiency and its relation to plant species abundance in a waterlimited grassland. Funct Ecol 15:605-614

Valladares F, Skillman JB, Pearcy RW (2002) Convergence in light capture efficiencies among tropical forest understory plants with contrasting crown architectures: a case of morphological compensation. Am J Bot 89(8):1275-1284

Vile D, Garnier É, Shipley B, Laurent G, Navas M-L, Roumet C, Wright IJ (2005) Specific leaf area and dry matter content estimate thickness in laminar leaves. Ann Bot London 96:1129-1136

Wang D, Heckathorn SA, Barua D, Joshi P, Hamilton EW, LaCroix JJ (2008) Effects of elevated $\mathrm{CO}_{2}$ on the tolerance of photosynthesis to acute heat stress in $\mathrm{C} 3, \mathrm{C} 4$, and CAM species. Am J Bot 95(2):165-176

Warren CR, Dreyer E (2006) Temperature response of photosynthesis and internal conductance to $\mathrm{CO}_{2}$ : results from two independent approaches. J Exp Bot 57(12):3057-3067 